\title{
SOBRE O MAL. JOSALBA FABIANA DOS SANTOS E JULIO JEHA. 2015. P. 197.
}

Luciano Cabral (UERJ)

Recebido em 25 fev 2016. Luciano Cabral doutorando em Literaturas de Língua Aprovado em 07 abr 2016. Inglesa (UERJ). Mestre em Literaturas de Língua Inglesa (UERJ). Bolsista CNPq entre 2013 e 2015. Editor da revista acadêmica online Palimpsesto-UERJ em 2013 e 2014. Membro dos grupos de pesquisa "Estudos do Gótico" e "A Voz e o Olhar do Outro", atuando principalmente nos seguintes temas: Narrativas de Serial Killers, Blank Narrative, Narratologia, Estudos Culturais, Teoria da Literatura, Literaturas Inglesa e Americana, e Literatura do Medo. Licenciado em Letras (língua inglesa e literaturas inglesa e americana) pela UERJ em 2012. Atualmente, pesquiso a construção do horror nas narrativas ficcionais de serial killers.

Contato: Iucianocabraldasilva@gmail.com 
Em Between the Monster and the Saint, livro em que reflete sobre os extremos do comportamento humano, Richard Holloway relembra um incidente de infância que ficou marcado em sua memória. Ele conta que, enquanto trabalhava como mensageiro em SOBRE
OMAL uma quitanda, certa manhã, os funcionários homens, entre cochichos e burburinhos, reuniram-se no depósito localizado nos

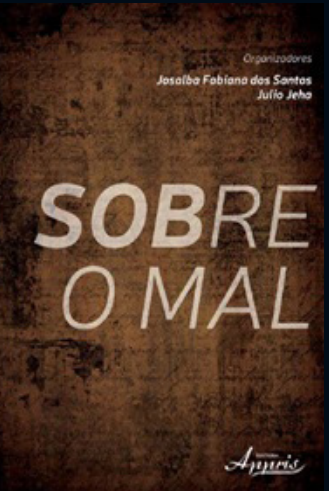
fundos do estabelecimento. Holloway, que tinha nove anos, acompanhou-os com o intuito de saber o que se passava. Em dado momento, entra uma funcionária no local, para buscar um produto qualquer. Os homens então agarram-na, colocam-na de pernas abertas sobre um balcão e o mais velho dentre eles enfia a mão por baixo do vestido da mulher e a apalpa. Feito isso, todos voltam aos seus afazeres e nada é mencionado sobre o assunto. A cena é descrita como possuindo um clima amistoso, e não hostil, pois todos riem, inclusive a funcionária. Entretanto, o que parece incomodar Holloway é menos o incidente em si do que sua participação no ataque: ele confessa ter segurado os tornozelos da mulher para que o funcionário pudesse melhor boliná-la. Tantos anos depois, Holloway ainda procura uma razão para aquele comportamento: o que foi que lhe fizera tomar parte do ataque nos fundos da quitanda? Em outras palavras, por que ele agiu de forma maldosa contra aquela mulher?

A narrativa de infância de Holloway parece confirmar a ubiquidade do mal. Nossa existência é perpassada por este estado e nossas atitudes (embora tentemos evitar) conduzem-nos para 
ele. Não surpreende então que o livro Sobre o Mal, organizado pela professora Josalba Fabiana dos Santos e pelo professor Julio Jeha, esteja interessado neste tema. Lançado em 2015 pela editora Appris, sua primeira edição conta com dez ensaios que se valem de arcabouços prevalentemente literários em suas abordagens, mas também contam com a interpretação psicanalítica e filosófica.

Uma das primeiras preocupações que se tem quando se reflete sobre o mal é saber o que ele é. Conhecer a natureza da atitude maléfica implica crer que ela pode ser entendida e posteriormente combatida. No entanto, se visto como o oposto do bem, o mal surgiria da ausência de comportamentos bondosos. Assim sendo, ele não existiria por si só, mas sua presença poderia ser mensurada apenas com base em seus efeitos, tais como o sofrimento, a dor e o medo. Ainda que seja complicado defini-lo, afirmar sua inexistência parece contrariar os fatos, como os relatos de Primo Levi sobre Auschwitz comprovam. Talvez seja preferível falar de males, no plural, já que homogeneizar os atos maldosos (dificilmente mal sofrido e mal perpetrado igualam-se, por exemplo) pode se tornar uma tarefa inglória.

Se é complexo definir o mal, apontar sua origem também tende a ser. Agostinho de Hipona preocupou-se com este ponto, posto que seu Deus cristão, como criador de todas as coisas, adquiria um caráter paradoxal diante da maldade presente no mundo, ou seja, ele seria o causador do bem e do mal ao mesmo tempo. Para resolver este impasse, Agostinho transferiu a responsabilidade pelo mal para o ser humano, através do livre-arbítrio. Para o teólogo, afastar-se dos preceitos divinos implicava rejeitar a bondade e, por consequência, escolher a maldade. 
Mas o livre-arbítrio invoca a total autonomia como fator para a escolha pelo mal, desconsiderando as influências sociais e psicológicas das atitudes humanas. Se somos considerados animais que interagem com nossos semelhantes - e se esta interação instiga nossos atos (ou parte deles) - nossas escolhas não são totalmente livres, mas também socialmente e psicologicamente determinadas. Por isso, Marx apontou para as relações de produção capitalista e Freud para as pulsões inconscientes como as causas do mal.

A despeito das posições marxista e freudiana, circula entre nós a expressão "pura maldade". Ela qualifica aquelas atitudes maldosas que parecem ser irracionais e inexplicáveis (como a narrada por Richard Holloway), ações sem origem ou causa, que podem nos levar a concluir que o mal não tem sentido - ou colocado de maneira inversamente proporcional, quanto menos sentido tem, mais maléfico ele se torna. Pode-se destacar então a característica banal que o mal assume nesta perspectiva, como frisou Hannah Arendt sobre o julgamento de Adolf Eichmann. O mal, entendido como um ato despropositado, incompreensível, sem origem ou causa, torna-se independente, passa a existir por si só (não mais mensurado pelos efeitos que provoca) e dispensa o bem como prerrogativa para sua compreensão.

Os ensaístas reunidos no livro estão cientes da ubiquidade e da complexidade do mal. Entendendo que as ações maléficas, como objeto de escrutínio, têm admitido múltiplos pontos de vista, suas interpretações apoiam-se em diferentes instrumentos críticos e teóricos. Julio Jeha aproxima o mal e a cidade ao analisar duas obras que apresentam a destruição de Chicago como pano de fundo, ambas escritas pelo jornalista e romancista Michael 
Harvey. Em The Fifth Floor (2008) e We All Fall Down (2011), Harvey oferece suas versões do grande incêndio ocorrido naquela cidade americana em 1871. Jeha apresenta-nos o termo "urbicídio", que, segundo ele, deve ser tomado como parte do campo semântico de genocídio, pois destruir a moradia das pessoas equivale a destruir as pessoas que ali habitam. Contudo, Jeha também explica que o termo não deve ser empregado para todo mal praticado contra a cidade, mas sim àquele cujo intuito é aniquilar a diferença por meio da destruição de suas bases materiais.

O mal sofrido e o mal perpetrado talvez estejam igualados apenas no suicídio. Praticar o mal contra si é reunir assassino e vítima na mesma pessoa. Émile Durkheim compreendia-o como um ato coletivo, afetando toda a sociedade. Por sua vez, Albert Camus, que comparou o ser humano em busca de sentidos para a vida a Sísifo empurrando seu pedregulho colina acima, via-o como uma ação estritamente individual. O ensaio de Josalba Fabiana dos Santos e Danielle Santos Rodrigues traz à tona este tema ao analisar a cartaconto "A Quem Interessar Possa", de Caio Fernando Abreu. As ensaístas investigam as reminiscências de um protagonista prestes a se suicidar, buscando aumentar as possibilidades de significação desta narrativa. Fluxo de consciência, pontuação escassa, excesso de memória e culpa são elementos que se unem para ativar uma certa hiperconsciência das mazelas históricas durante um período caro para nós brasileiros: a ditadura militar.

Paul Ricoeur e Theodor Adorno asseveram que, por ser essencialmente um mistério indecifrável e impenetrável, o mal não pode ser representado. Mas, embora possivelmente reconheçamos ser inviável decifrá-lo, podemos ao menos metaforizá-lo, e o 
mais frequente modo de fazê-lo é através de monstros. Como materializações da maldade, os monstros transgridem categorias. Por conta disso, são habitualmente classificados como coisas contraditórias e intersticiais, abarcando sempre mais de uma categoria, tais como morto/vivo, animal/humano e corpo/máquina. Além do mais, sua transgressão envolve a incompletude (sem traços característicos que os definam), a informidade (exclusão da possibilidade de categorização) e deformidade (em desacordo com parâmetros de normalidade). Este último traço, mais especificamente, é importante para o ensaio de Ana Claudia Aymoré Martins. A professora lança mão do quadro O Pesadelo, do pintor suíço Henrich Füssli para iniciar sua análise da imagem monstruosa no romance São Bernardo, de Graciliano Ramos. Ao esmiuçar tanto os atributos físicos quanto os psicológicos do violento Paulo Honório, Aymoré Martins destaca suas deformidades monstruosas a fim de construir uma teratologia deste personagem.

Mesmo que os efeitos de fenômenos como enchentes, furacões e terremotos sejam catastróficos, desastres naturais não são normalmente compreendidos como uma atitude maléfica. Sendo uma das três fontes de sofrimento listadas por Freud, a força da natureza, indomável e severa, tende a ser tomada mais como uma fatalidade do que como uma intencionalidade. A intenção de causar o mal pressupõe uma consciência, e é assim que este mal, intencional e consciente, associa-se à moralidade - ou melhor, ao seu contrário, à imoralidade. Maurício Cesar Menon trata deste mal que é praticado conscientemente com base no conto Bucólica, de Monteiro Lobato. Seu ensaio procura reconhecer o mal, corporificado na figura do monstro, que invade as narrativas brasileiras por conta 
da colonização europeia, daí encontrando condições propícias no Romantismo para se fortalecer e se alastrar. $\mathrm{O}$ ensaísta esclarece que a amplitude territorial, o isolamento de algumas comunidades rurais (afastadas das áreas urbanas), o sincretismo religioso, assim como fatores sociais e culturais, forneceram material para a ficção gótica dos escritores. Estes, adaptando temas sombrios trazidos da Europa para a conjuntura nacional, foram responsáveis pela disseminação de temas ligados ao insólito, aos monstros e ao mal. A análise do conto de Lobato - que narra o caso de uma mãe que, por crueldade, deixa a filha deficiente morrer de sede - corrobora a alegação de Menon.

Das três fontes freudianas de sofrimento, nossa relação com o outro é a que mais nos aflige, segundo o psicanalista. Estamos propensos a considerar a imprevisibilidade das ações humanas como algo temeroso, justamente porque tais ações são aleatórias e desconhecidas. Zigmunt Bauman aponta que o medo que sentimos tem raiz na incerteza e na ignorância da ameaça que está diante de nós. Quando não sabemos o que podemos fazer para enfrentá-la, pará-la ou afastá-la, ficamos amedrontados. Entretanto, Bauman também explica que, mais recentemente, nós sofremos tanto por ameaças diante de nós quanto por ameaças distantes e menos imediatas. Este sofrimento é chamado por ele de "medo derivado" e caracteriza-se por um sentimento perpétuo de insegurança e invulnerabilidade (que perdura mesmo que o perigo não seja iminente), que mais se assemelha à sensação conhecida por nós como angústia. São estes dois sentimentos, medo e angústia, que interessam à investigação de Luiz Eduardo da Silva Andrade. Em seu ensaio, ele demonstra como o romance $A$ Menina Morta, de Cornélio Penna, utiliza as estratégias literárias para dobrar e desdobrar - ora 
revelando e ora escondendo - uma narrativa que gira em torno dos preparativos para o sepultamento da filha do Comendador, morta precocemente. O problema que o ensaísta coloca localiza-se na conciliação destas duas emoções: a presença do Comendador e a ordem estabelecida representam o medo; o clima de insegurança e a sensação de vigilância constante marcam a angústia.

Quando nos servimos da óptica cristã, o mal passa a ser qualquer conduta que negue as prerrogativas divinas. Não foi gratuito, então, dar o nome de mandamentos ao decálogo recebido por Moisés, pois crê-se que, estipulados pelo próprio Deus, estes teriam força de lei. Se a ficção corporifica as atitudes maldosas através dos monstros, o cristianismo elege Judas Iscariotes como a figura histórica que melhor representa o mal. Judas é tido como o mais malévolo não só por pecar contra os mandamentos, seu pecado maior foi tramar contra Jesus, pois traí-lo equivaleu a trair o próprio Deus. Tão odiado a ponto de ter seu evangelho rebaixado à condição de apócrifo, Judas perdeu qualquer direito de ter sua história como um dos livros da Bíblia. No entanto, este personagem nunca foi esquecido literariamente. Se se rejeita uma versão bíblica da vida de Judas, suas versões ficcionais proliferam. Este é o interesse do ensaio de Lyslei Nascimento e Késia Oliveira. As ensaístas examinam as representações do mal nas obras de ficção brasileiras em que Judas está presente. Elas reconhecem que há uma relativização do mal, já que, na paráfrase, Judas é retratado como uma encarnação maléfica; mas, na paródia, ele está afastado da qualidade de traidor.

O cristianismo também tem seus monstros. Os anjos, que auxiliam Deus, tem sua contrapartida nos demônios, entidades 
sempre atreladas ao diabo, o arauto do mal por excelência. Tereza Virgínia Ribeiro Barbosa faz emergir estes entes infernais ao admitir que o diabo assemelha-se à literatura, pois ambos têm o poder de ser, a um só tempo, reais e imaginários. Indo mais além, a professora declara que não há espaço mais propício para o mal do que o literário, "lugar do imaginado, do difuso e do misturado". Seu ensaio resgata o mito das sereias, nas viagens de Odisseu, para construir a crença de que a literatura possui uma voz bela e doce, mas diabólica. Para embasar suas afirmações, Tereza Virgínia aposta na relação entre Maria Mutema e o padre Ponte, personagens do romance Grande Sertão: Veredas, de Guimarães Rosa. Maria Mutema pratica o mal sem razão (fazendo jus à expressão "pura maldade") ao confessar uma paixão inexistente. O padre então é morto não por faca mas pela palavra, tal qual faz o canto das sereias, na Odisséia.

Mesmo que se resista à ideia de que a literatura como um todo seja morada para o mal, um gênero ao menos não escapa desta alegação. A ficção de horror, que privilegia espaços lúgubres, personagens macabros, crimes e monstros, vem evocando a maldade em suas histórias desde o castelo de Otranto, no século dezoito, até os marginais e assassinos em série do nosso presente cotidiano. A popularidade do gênero é inquestionável. Porém, quando a rubrica moral entra em cena, este segmento recebe duros julgamentos. Os críticos que rechaçam a ficção de horror atacam tanto o leitor quanto o autor: aquele seria um masoquista e este um psicótico. Em seu ensaio, Júlio França, atuando "como o advogado do diabo", defende o horror e discute sua utilidade. Para ele, o caminho para lidar apropriadamente com o tema não é saber para que serve a narrativa de horror. É necessário inverter os elementos e indagar 
para que serve o horror nas narrativas. O ensaísta acredita que somente após esta inversão será possível aceitar que o mal pode ser educativo. Tais histórias, embora afrontem os leitores, fazemnos ao mesmo tempo em que os obrigam "a repensar seus modos de encarar o mundo".

Que seja talvez uma derrota admitir, mas o fato é que o mal participa da existência do ser humano, ora por atração e ora por rejeição. Isso pode ser explicado pelo caráter relativo da maldade e pela natureza multifacetada do indivíduo. Afinal, não há nenhuma novidade em dizer que os conceitos de bem e de mal são, em última instância, circunstanciais. Este é um dos pontos discutidos por Ana Leal Cardoso. Em seu ensaio, a professora aborda a presença da maldade na vida moderna, aproximando as reflexões do filósofo Paul Ricoeur das análises psicológicas de Carl Jung e John Sanford. Este último por exemplo, de maneira fatalista (ou realista), sustenta que o mal é inevitável. Ricoeur, por sua vez, enxerga uma certa duplicação da ação maldosa ao constatar que "o mal cometido por uma pessoa encontra seu correlato no mal sofrido por outra". Assim, o filósofo detecta na conduta violenta (pois toma mal e violência como sinônimos) a raiz do mal, e sugere que ações éticas e políticas que contribuam para diminuir a violência podem reduzir o sofrimento humano.

O último ensaio do livro traz as palavras de Agostinho de Hipona em diálogo com Plotino. Cícero Cunha Bezerra interpreta o mal adotando uma perspectiva que funde as tradições cristã e neoplatônica. Da primeira, o ensaísta salienta a afirmação agostiniana de que a maldade não está nas coisas, mas no uso que se faz delas. Este uso tem estreita relação com as escolhas e desejos 
do indivíduo. Neste sentido, o mal acontece quando se opta por desviar das virtudes cardeais - estas sendo a justiça, a prudência, a fortaleza e a temperança. Da segunda tradição, Bezerra extrai a compreensão do mal a partir da concepção plotiniana de matéria. O professor explica que, sendo uma não-forma, o mal portanto só pode ser apreendido como a ausência de todo bem.

Os dez ensaios que o livro contempla apresentam-nos o mal de formas diferentes e em espaços distintos. Neles, os atos maldosos estão na cidade, no suicídio, corporificados em um personagem ou na própria literatura. Os ensaístas reunidos em Sobre o Mal sabem entretanto que o tema não se esgota nesta publicação. A maldade que é hábil em se multiplicar literariamente, é também capaz de provocar academicamente. Outras edições, sem dúvida, serão produzidas. Não importa se visto em seu estado puro ou através de seus efeitos, o mal tem sua ubiquidade garantida nestas páginas. 